\title{
LETHAL INFLUENCE FACTORS OF NATURAL AND Preformed Fragmentation Projectiles
}

\author{
ZECEVIC, B.; TERZIC, J.; RAZIC, F. \& SERDAREVIC-KADIC, S.
}

Abstract: Low intensity warfare had many impact on reducing logistic costs during field operations. It influenced the development of new large caliber HE projectiles. Concerning increasing lethal efficiency at target, the focus is at development of modern projectiles with natural, embossed and preformed fragmentation. Modern natural fragmentation projectiles characterize excellent aerodynamic properties, use of high strength steel with high fragmentation characteristics and denser high energy materials. Artillery projectiles with preformed fragments are usually equipped with large amount of preformed spherical or cubical fragments made of steel or tungsten. Modern unguided rocket warheads are based on embossed fragmentation or preformed warheads concept. There are limited data about real lethal effects of these projectiles. This paper presents available data and research results of embossed fragmentation warhead $122 \mathrm{~mm}$ and prefragmented warhead $128 \mathrm{~mm}$, which are conducted in Bosnia and Herzegovina.

Key words: projectile, lethal, warhead, prefragmented, rocket
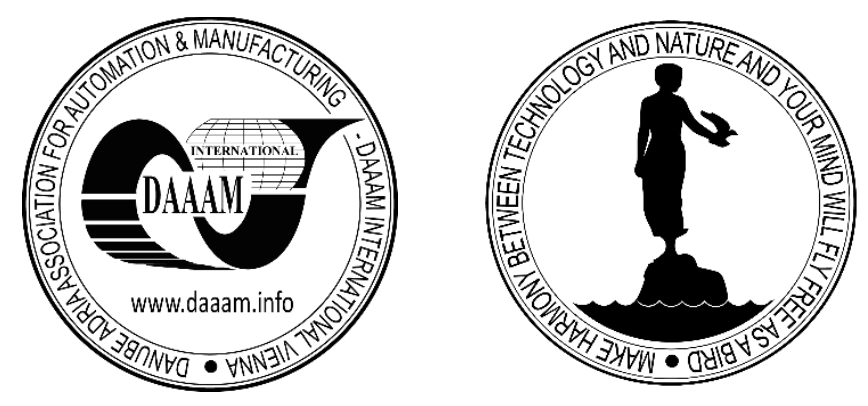

Authors' data: Prof. Dr. Sc. Zecevic, B[erko]; Assist. Prof. Dr. Sc. Terzic, J[asmin], Senior Assistant Razic F[aruk], Assist. Prof. Dr. Sc. Serdarevic-Kadic S[abina] Faculty of Mechanical Engineering, University of Sarajevo, Vilsonovo setaliste 9, Sarajevo 71000, Bosnia and Herzegovina, zecevic@mef.unsa.ba, terzic@mef.unsa.ba, razic@mef.unsa.ba, serdarevic@mef.unsa.ba.

This Publication has to be referred as: Zecevic, B[erko]; Terzic, J[asmin]; Razic, F[aruk] \& Serdarevic-Kadic, S[abina] (2015). Lethal Influence Factors of Natural and Preformed Fragmentation Projectiles, Chapter 20 in DAAAM International Scientific Book 2015, pp.219-234, B. Katalinic (Ed.), Published by DAAAM International, ISBN 978-3-902734-05-1, ISSN 1726-9687, Vienna, Austria

DOI: $10.2507 /$ daaam.scibook.2015.20 
Zecevic, B.; Terzic, J.; Razic, F. \& Serdarevic-Kadic, S.: Lethal Influence Factors o...

\section{Introduction}

Low intensity warfare had significant impacts on needs for reducing logistic costs during certain field operations. Consequences of these particular needs had directly influenced the development of new large caliber HE projectiles with longer range, less dispersion on target, greater accuracy and precision and increased lethal efficiency.

During fragmentation process, modern HE projectiles should have large number of fragments to increase probability of hit on target, and sufficient spatial fragment density enabling multiple hit on a target with enough kinetic energy for target penetration. Lethal fragment range depends on initial velocity, fragment ejection angle, mass and shape of fragment. From the applied technology point of view for increasing lethal efficiency of large caliber projectiles at target, natural fragmentation, embossed fragmentation or preformed fragmentation technology is applied. Choice of technology is depending on technological capabilities of country that is producing the projectiles and financial capabilities of customer/buyer.

Natural fragmentation HE artillery projectiles technology is characterized by wasted mass/energy, low cost of manufacturing and least mass efficient at target. Modern natural fragmentation projectiles characterizes high launch velocities, excellent aerodynamic properties (better slimness of front part of projectile and lower slimness of cylindrical part), possibility of using base-bleed generator or hollow base configuration, use of high strength steel with extraordinary fragmentation characteristics and use of more dense high energy materials with properties of IM.

Embossed fragmentation projectiles or ammunition technology is characterized by less wasted mass/energy, improved lethality and low cost of manufacturing. This kind of technology is not applicable in artillery projectiles since there is high axial acceleration during the launching phase and this could jeopardize structural strength of the projectile body. This kind of fragmentation has been in use for a long time with guided and unguided rocket warheads. Inside of the warhead there are integrated segments which have partially formed fragments (V-Notch Scoring). In addition, this technology is used in modern hand grenades.

Preformed fragmentation projectiles or warheads technology characterizes efficient mass/energy, optimized lethality and more cost of manufacturing and most mass coefficient (Clark et al., 2011). Modern artillery projectiles with preformed fragments are usually equipped with large amount of pre formed fragments which are formed as a sphere or a cube made of steel or tungsten and positioned in front and in the middle of projectile built in cured polymer matrix. These projectiles or warheads use modern IM explosive charges and fuzes with multimodal functions. This kind of approach in increasing lethal efficiency was originally represented in HE-PFF projectiles for anti aircraft combat or against guided missiles, $40 \mathrm{~mm}, 56 \mathrm{~mm}$ and $76 \mathrm{~mm}$ caliber, considering high prices of the ammunition and value of targets which are targeted. Since there are a lot of warfare in urban areas, development of preformed projectiles with controlled lethal zone and large density of efficient fragments in that zone is intensified in recent years.

Requirements for increased lethality of artillery projectiles are justified when 
analysis of launched projectiles needed for neutralization of certain types of targets is done. Objectively, these kinds of information were unavailable for public release. So realistically, efficiency of some weapon system comes down to optimizing the balance of cost and performance. Figure 1 and Table 1 presents comparative view of No. launch for three different HE projectiles for four types of targets.

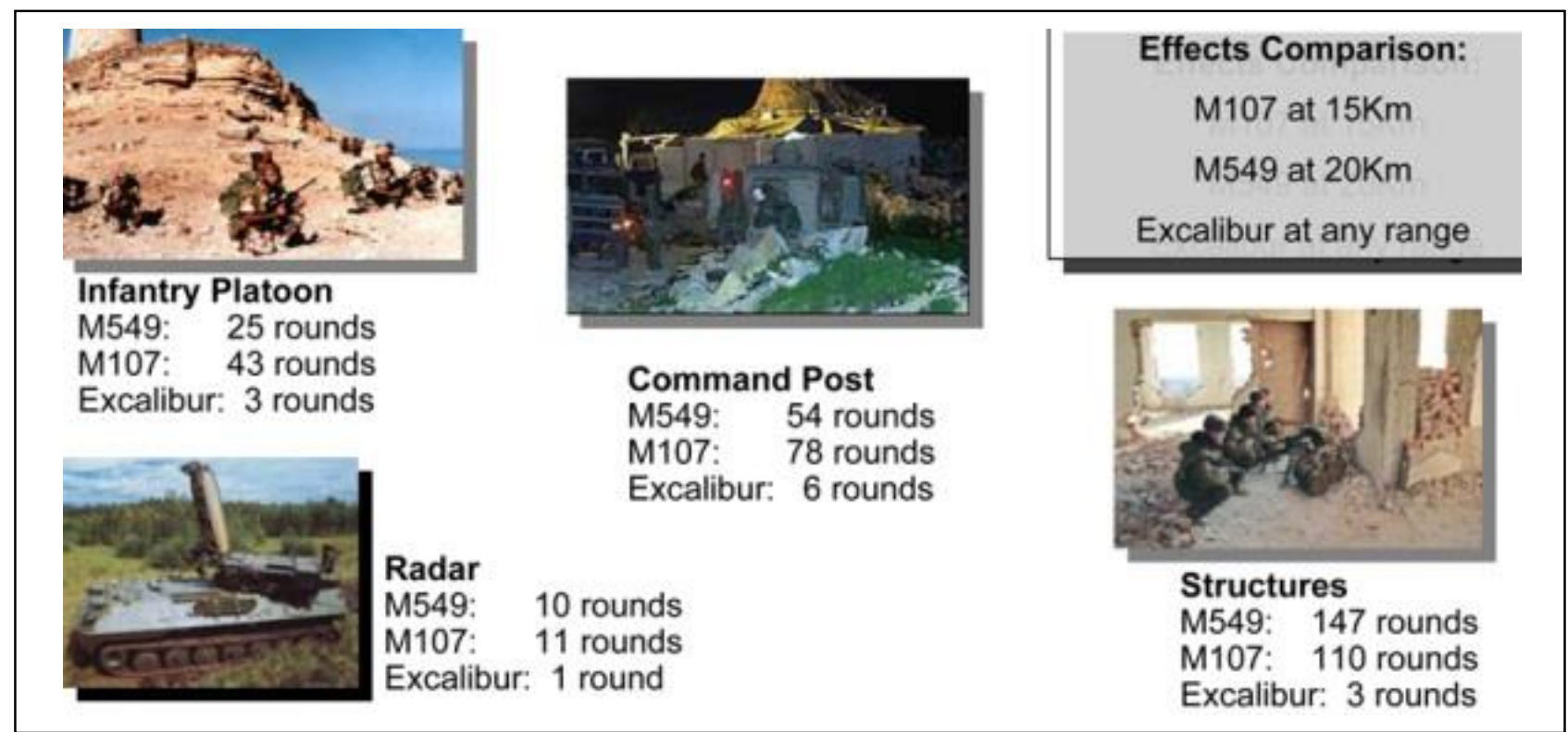

Fig. 1. Comparative view of No. Launch of three different HE projectiles for four different types of targets (Anon 2008; DeMella 2008)

\begin{tabular}{|c|c|c|c|}
\hline Target & $\begin{array}{c}\text { Excalibur } 155 \mathrm{~mm} \\
\text { (unitary) } \\
\text { (At any range } \\
\text { out to } 40 \mathrm{~km} \text { ) }\end{array}$ & $\begin{array}{c}\text { M549 } 155 \mathrm{~mm} \\
\text { HE RAP } \\
\text { (20 Km range to } \\
\text { target) }\end{array}$ & $\begin{array}{l}\text { M107 } 155 \mathrm{~mm} \\
\text { HE, } \\
\text { (15 Km range to } \\
\text { target) }\end{array}$ \\
\hline Infantry platoon & 3 rounds & 25 rounds & 43 rounds \\
\hline Radar & 1 rounds & 10 rounds & 11 rounds \\
\hline Command post & 6 rounds & 54 rounds & 78 rounds \\
\hline Structure & 3 rounds & 147 rounds & 110 rounds \\
\hline
\end{tabular}

Tab. 1. Tabular summary of projectiles needed for destruction of one target

The fact that neutralization of structure typed target requires launching of $110 \mathrm{HE}$ projectiles, $155 \mathrm{~mm} \mathrm{M107}$, at range of $15 \mathrm{~km}$ to target sounds astonishing.

According to Dominic DeMella, while shooting at target group that consists of three tanks, six APC's, eight trucks, six AA's and one jeep, 432 HE projectiles $155 \mathrm{~mm}$ M107 are launched. Eight targets have been hit, of which two tanks, four APC's and two trucks.

Statistical analysis of HE ammunition efficiency against personnel shows that the average amount of HE projectiles $105 \mathrm{~mm} \mathrm{M1}$ that needs to be launched for one kill is 31,6 (launched 7.079 projectiles), and 13,6 pieces of HE projectiles $155 \mathrm{~mm}$ M107 (launched 3.465 projectiles).

The request for the development of modern high explosives projectiles for guns 155mm ARCHER states: 
- The HE projectile shall be optimized for effect against soft and semi-hard targets,

- Priority to semi-hard targets like unarmoured and light armoured vehicles, i.e. BMP2. (Remark: Effect shall be understood as penetration of vehicle and/or incapacitation of all attached equipment such as optical instruments, antennas, tires, etc.),

- All Explosive shall be qualified according to STANAG 4170.

There are very few data in available literature about lethal effects of natural fragmentation projectiles and preformed projectiles.

\section{Natural fragmentation projectiles}

Artillery projectile or rocket warheads are usually two-dimensional axial symmetric. Detonation process starts when fuze, which is located on the top of projectile, hit at steel and initiates explosive train. Detonation pulse from fuze activates buster charge which is found inside of explosive charge of projectile creating necessary conditions for beginning of detonation process of explosive charge of projectile. Shock wave is moving through explosive charge, and behind the shock wave are detonation products which are acting upon the inner structure of projectile body. It is important to point out that detonation process is not instantaneous and that it lasts for tens of microseconds.

There is a radial expansion of projectile body in the part of projectile where transformation of explosive charge into detonation products occurs. Due to defects in crystal structure of material, cracks start to appear very rapidly and detonation products vent through. Experimental research using x-ray technology and high speed video techniques shows that the volume of projectiles is increased several times before fragmentation of warhead occurs (Fig. 2 and Fig. 3).

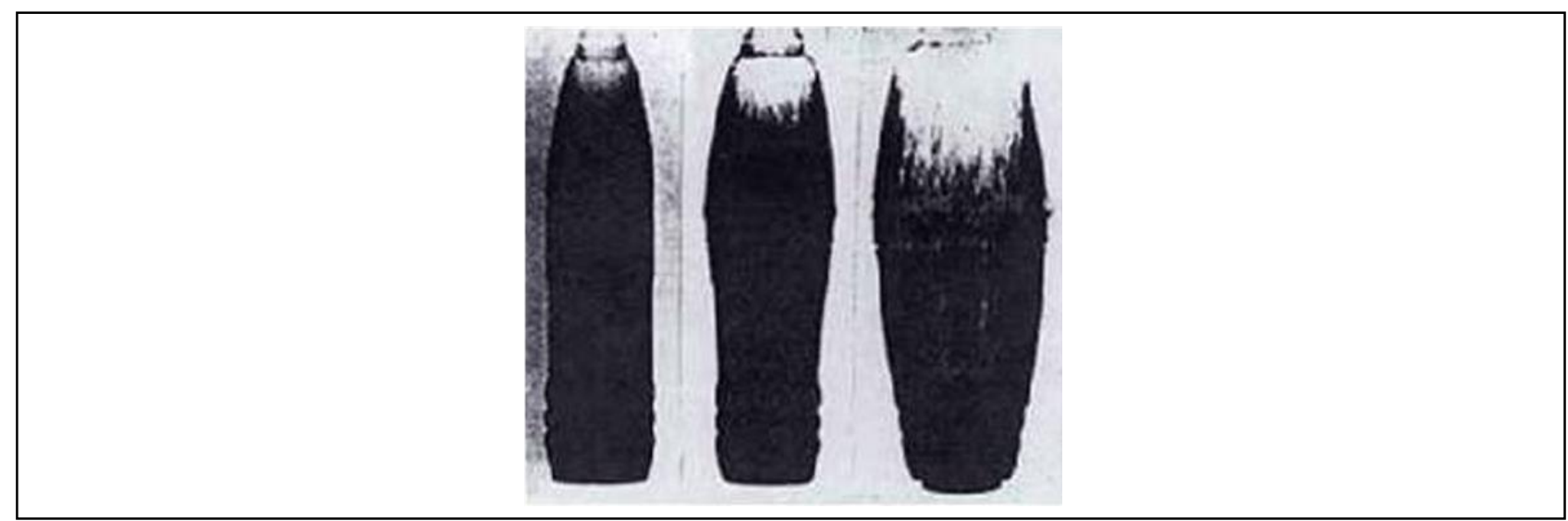

Fig. 2. Radial expansion of projectile body during detonation process (Odintsov, 1997)

The moment of fracture of body structure depends on chemical composition, crystal structure characteristics of material and its purity, mechanical characteristics of material (ultimate tensile strength in dynamic conditions, toughness, contraction etc.), physical and energetic characteristics of explosive charge, its density and homogeneity etc. 


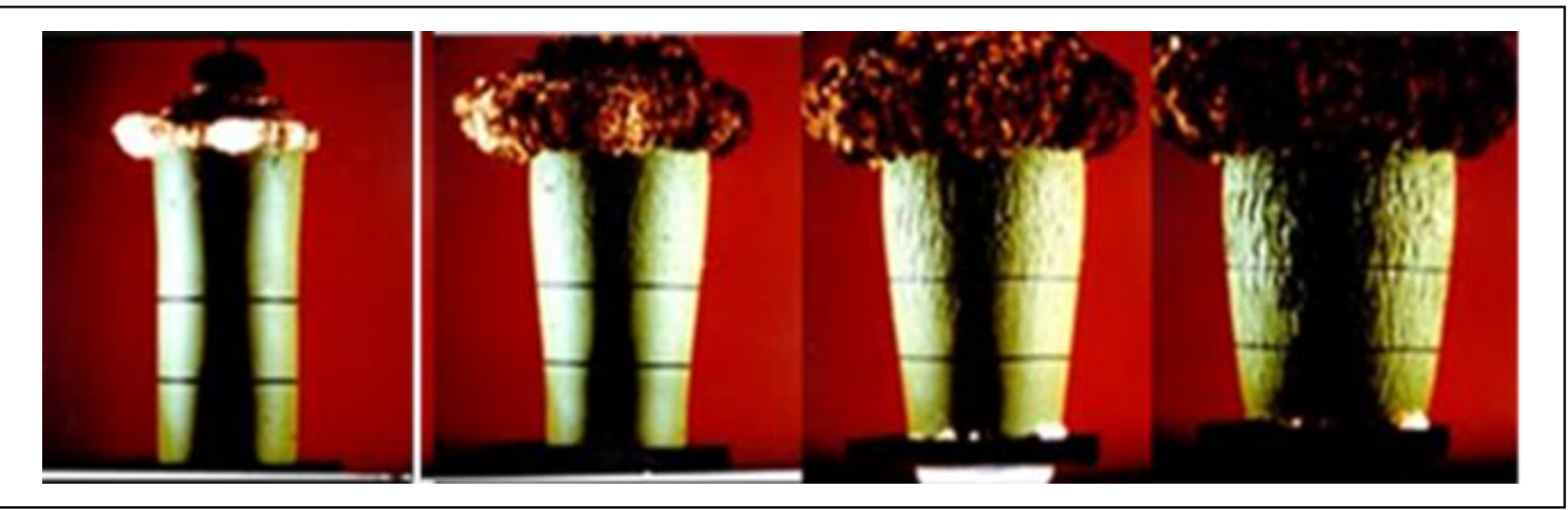

Fig. 3. Expanding sequences of cylinder at explosive detonation (500.000 frames/s) (Cordin, 2003)

According to Zecevic at al., during projectile body expansion due to detonation products, projectile body thickness is decreasing (Conservation of mass of projectile body), and since projectile has abilities to significantly increase its initial volume, the ability for forming larger number of fragments with lower mass is also increased, and this is very important in artillery projectiles.

Natural fragmentation projectiles or warheads results in a wide range a random distribution of fragment sizes (masses and geometry). The drag coefficients for projectile fragments formed by a natural fragmentation cannot be determined precisely for certain Mach number because every fragment is unique by its shape and mass. The uniformity of mass and shape of a fragment, during the natural fragmentation process of HE projectile, does not exist. (Fig. 4). The spatial distribution of fragments of body projectile is not uniform. Naturally fragmenting projectile typically experience shear fracture initially into initial long axially oriented bands. Effective shear and or radial fracture of body projectile depending on toughness, brittleness and grain size of structure materials and power of the shock wave detonation and magnitude of the impulse explosive charge.

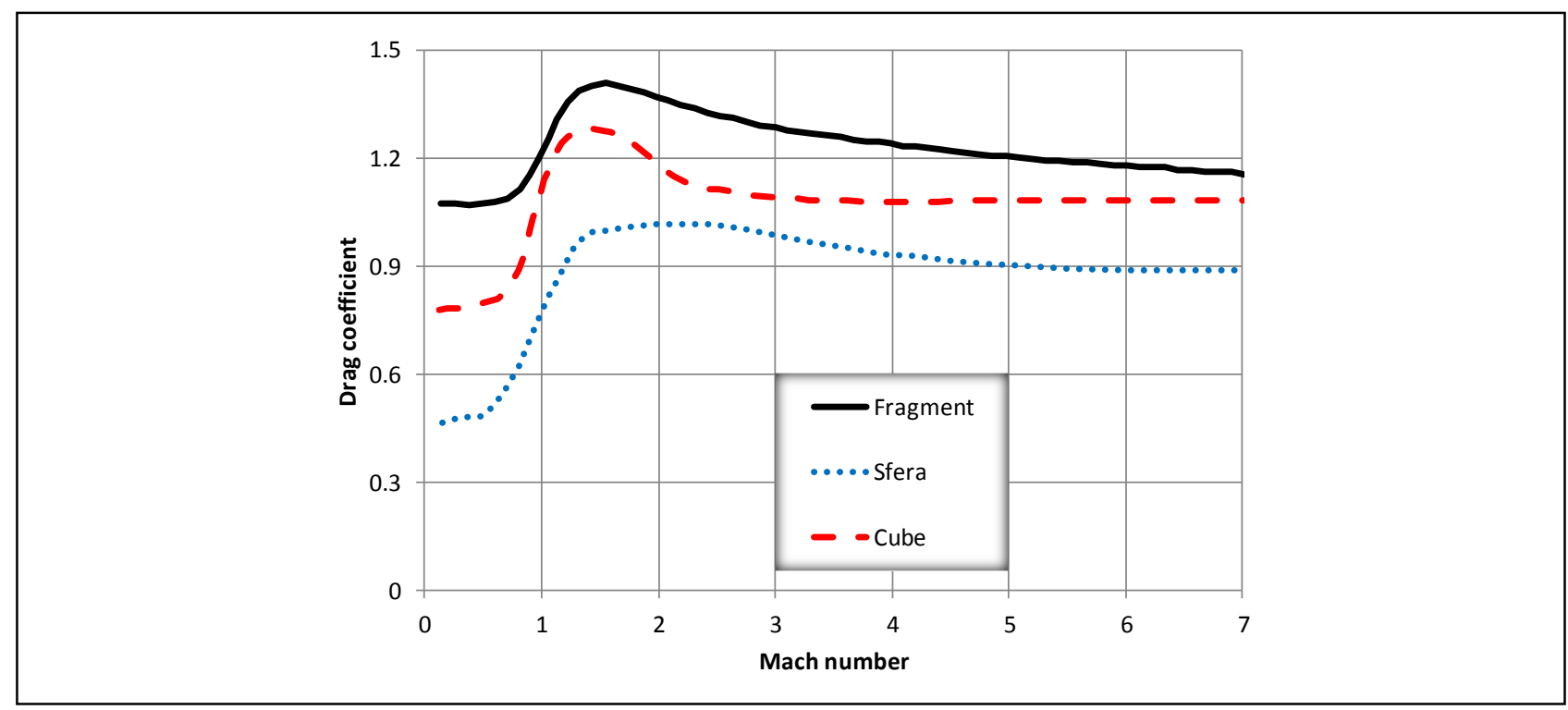

Fig. 4. Aerodynamic drag coefficient for three different fragment types (Harling \& Pelo, 2014) 
Zecevic, B.; Terzic, J.; Razic, F. \& Serdarevic-Kadic, S.: Lethal Influence Factors o...

The maximum velocity (95 to $100 \%$ of the Gurney velocity) is that achieved at the end of fragment acceleration with the fragments at a radius of about 1.6 to 1.8 times the initial warhead radius (Lloyd, 1999). Too early venting through cracks of projectile body can result in a drastic decline of initial fragment ejection velocity. Because of that, it is very important to have a good knowledge of materials and thermal parameters of projectile body processing, parameters of explosive charge and explosive train.

Conventional artillery projectiles with natural fragmentation have a small ratio of explosive charge to mass of projectile body and it is between 0,15to 0,25. Modern artillery projectiles tend to increase this ratio to 0,25 to 0,30 .

Figures 5. to 7. clearly show how the use of new materials and new design concepts of $\mathrm{HE}$ projectiles can significantly influence the lethal zone increasing (Zecevic at al., 2004). Swedish projectile 155mm HEER-FB/BB represents the top of the artillery projectiles, it has mass of $45 \mathrm{~kg}$ and mass of TNT explosive charge of 9,15 $\mathrm{kg}$. Ratio of mass of explosive charge to mass of projectile body is 0,255 . Range of this projectile is $42 \mathrm{~km}$ at maximum speed of $970 \mathrm{~m} / \mathrm{s}$. Slimness of projectile with fuze is 5,86 calibar.

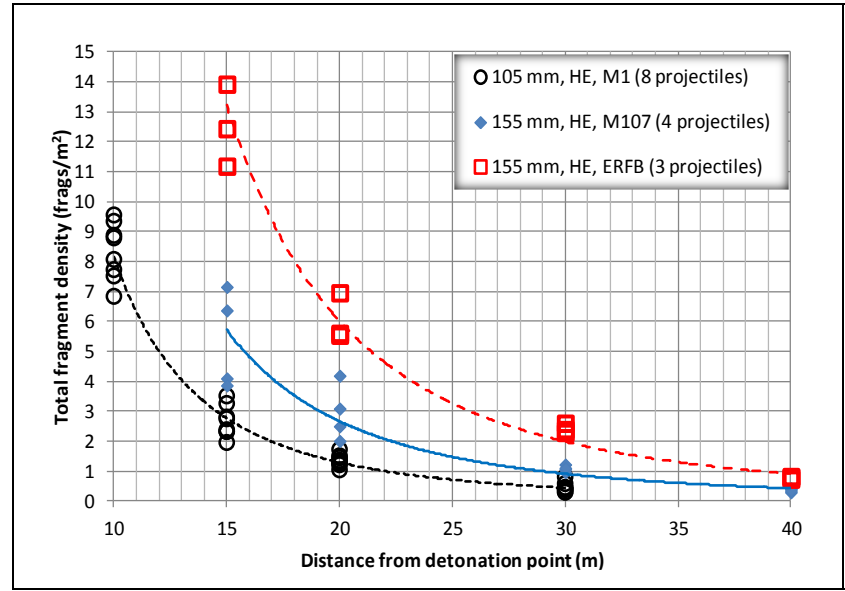

Fig. 5. Change in fragment density as function of distance of centre of explosion

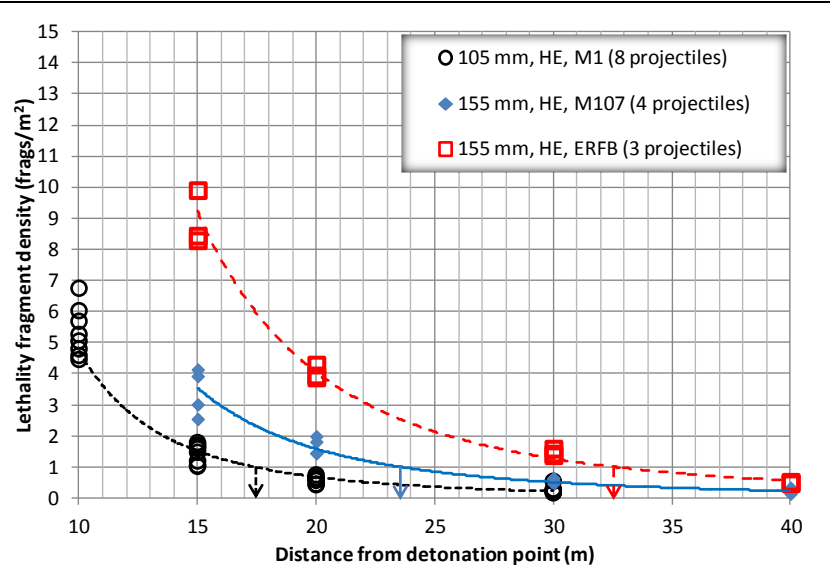

Fig. 6. Change in lethal fragment density as function of distance of centre of explosion

Figure 7. show that out of total number of fragments created in explosion of HE projectile, in area of $2 \mathrm{~m}$ height, number of lethal fragments which have energy of $80 \mathrm{~J}$ is $30 \%$ to $70 \%$ of total number of fragments, depending on caliber, model of $\mathrm{HE}$ projectile and distance from centre of explosion. However, change of lethal fragment contribution in total number of fragments is not directly proportional to the distance from the centre of explosion, it is dependable of mass distribution characteristics an shape of fragments. Bearing in mind that experimental research data of testing $\mathrm{HE}$ projectiles in four sector arena shows large number of fragments grouped in central bundle that fits the polar sector of $80^{\circ}$ to $105^{\circ}$ measuring from the tip of projectile [Zecevic at al., 2004]. 


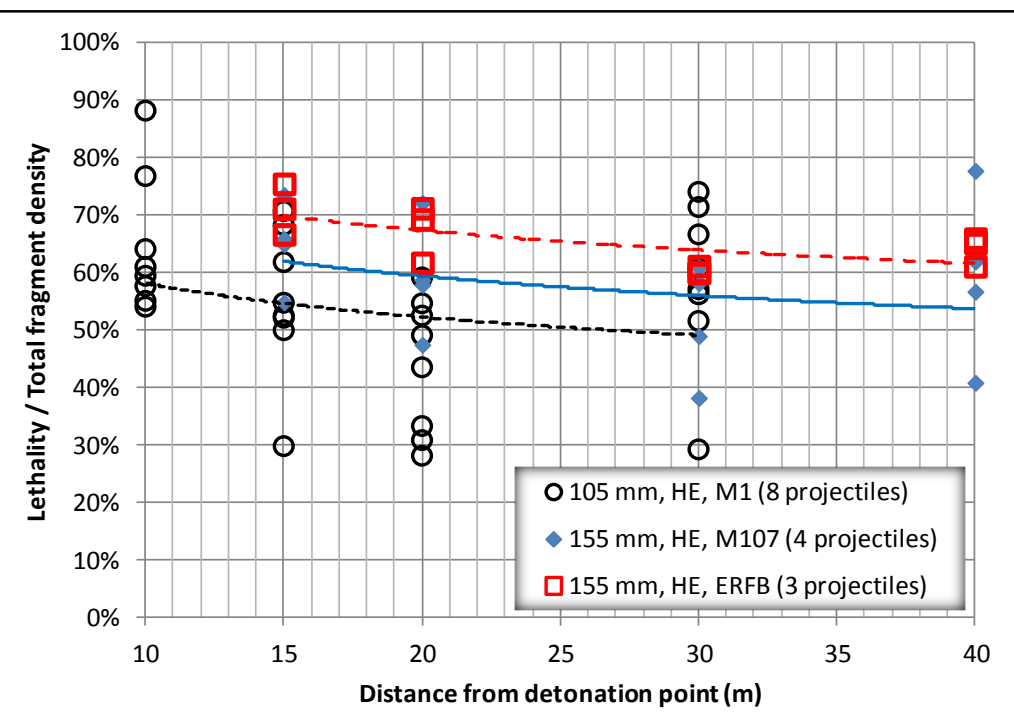

Fig. 7. Lethal fragments contribution of HE projectiles as a function of total number of fragments in area around the explosion, height $2 \mathrm{~m}$

Materials for construction of modern American artillery projectile bodies by forging are usually AISI 1045, AISI 1090, AISI 1340, AISI 4340, AISI 9260 and HF - 1 steel. After forging of projectile body various heat treatments are applied with two main goals; first to achieve convenient level of structural strength of projectile (safety reliability) during launching phase, and second to achieve the required lethal efficiency at target (Functional reliability). HF-1 steel is the No.1 steel in metallurgy for high fragmentation projectiles. Heat treatments are chosen to obtain the necessary yield strength and while varying the warhead microstructure (Durkin, 2001). The projectile can be configured with either a Boat Tail or Base Bleed which are field interchangeable. Intensive research about development of new fragmentation steels for modern artillery projectiles is also conducted in Russia. In Special Engineering Research institute of the Bauman MGTU steels S-60 and 45Khl are developed, and they match conventional fragmentation steels. Beside this, silicon spring steel 60S2, eutectoid pearlitic steel $80 \mathrm{G} 2 \mathrm{~S}$ and hypereutectoid pearlitic-cement steel 11OG2S are developed. In terms of composition and physicomechanical characteristics, steels 60S2 and 11OG2S are close to high fragmentation steels AISI 9260 and HF-1 patented in USA (Odintsov, 1997).

The most practicable trend in improvements to classical HE projectiles with natural fragmentation shell involves a rational combination of the shell material (technological process of its manufacture including heat treatment) and explosive.

Modern $155 \mathrm{~mm}$ extended range full-bore HE projectiles (Jane's Ammunition Handbook 2001-2002) have body made by forging from AISI 9260 steel or a similar grade steel. The explosive payload can vary but a typical explosive filling is $8,2 \mathrm{~kg}$ of Composition B and manufactured using AISI 9260 steel will result in an average of 7.750 fragments. The south African $155 \mathrm{~mm}$ ERFB produces approximately 7.000 fragments (probably HF-1 steel) with an individual mass larger than $0,5 \mathrm{~g}$ using nominal payload of 8,71 kg of RDX/TNT 50:50. 
Zecevic, B.; Terzic, J.; Razic, F. \& Serdarevic-Kadic, S.: Lethal Influence Factors o...

HE projectile body is manufactured of forged steel AISI 1045. The $155 \mathrm{~mm} \mathrm{HE}$ M107 filling may be either $6,62 \mathrm{~kg}$ of cast TNT or $6,985 \mathrm{~kg}$ of Composition B. A TNTfilled $155 \mathrm{~mm}$ HE M107 will produce approximately 1.950 fragments on detonation.

\section{Preformed projectiles}

Projectile or warheads with preformed fragments allow the choice of mass, shape and dimensions of the fragments. Significant deformities of the fragments do not occur during detonation. Initial velocity of the fragments during detonation in warheads with similar diameter and $\mathrm{C} / \mathrm{M}$ ratio is $10 \%$ lower than initial velocity during natural fragmentation of the projectile (Held, 1993). Warheads with pre-formed fragments are structurally more complex and the body usually consists of two layers. Structural layer has the task of providing integrity of the structure during launching phase and during the phase of target impact. That part of metal structure fragments naturally during detonation process. The second layer consists of small density matrix (made of aluminium or, more recently, of cured polymer matrix), which has the task to compactly hold preformed fragments and to allow certain radial expansion of the layer under the influence of detonation products for a shorter time period. Every material of the carrier matrix will decrease initial velocity of fragments, because the thickness of warhead body is realistically increased relative to the thickness of explosive charge. Premature and excessive leakage of gases through the structure of carrier of preformed fragments will directly influence on the fragments initial velocity and lethal efficiency of the projectile.

Position of preformed fragments in the structure of projectile or warhead depends on the type of projectile and the level of axial acceleration that the projectile is being exposed to during launching phase. This fragmentation technology has long been used only in guided and unguided rocket warheads. The first successful step forward with the projectiles that had significant axial acceleration in launching phase has made the RUAG company (now SAAB) with MAPAM mortar projectiles caliber 60 and $81 \mathrm{~mm}$ (RUAG Land Systems, 2004).

Preformed fragments can be in the form of sphere, hexagonal, cube or parallelepiped. Shape and dimensions of preformed fragments objectively affect the inner space of the projectile or warhead that is designed for explosive charge. They are directly influencing on velocity of fragments at the moment of detonation. Cubical shaped fragments provide optimum packaging in liner and have maximal lethal efficiency with minimum air drag. However, with this type of preformed fragments high fragment velocities cannot be achieved. It is important to point out that the price of manufacturing cubical fragments is very high.

If there are restrictions in volume and mass of projectile, then cubical shaped fragments are not good solution. Optimum shape in this case would be parallelepiped where two of its sides do not exceed 1,5 times the thickness (thinner side is positioned in the radial direction of projectile) (Held, 1993).

BOFORS ammunition $40 \mathrm{~mm}$ 3P IM and $57 \mathrm{~mm}$ 3P IM is the top representative designer solution in anti aircraft HE ammunition (3P ammunition - Prefragmented Programmable Proximity fuzed ammunition) (Borén, 2003). Projectile $40 \mathrm{~mm}$ 3P IM 
(Fig. 8) contains more than 3.000 tungsten spheres, diameter of $3 \mathrm{~mm}$. Lethal area is $140 \mathrm{~m}^{2}$. Projectile $57 \mathrm{~mm}$ 3P IM contains more than 8.000 tungsten spheres, diameter of $3 \mathrm{~mm}$. Lethal area is $400 \mathrm{~m}^{2}$.

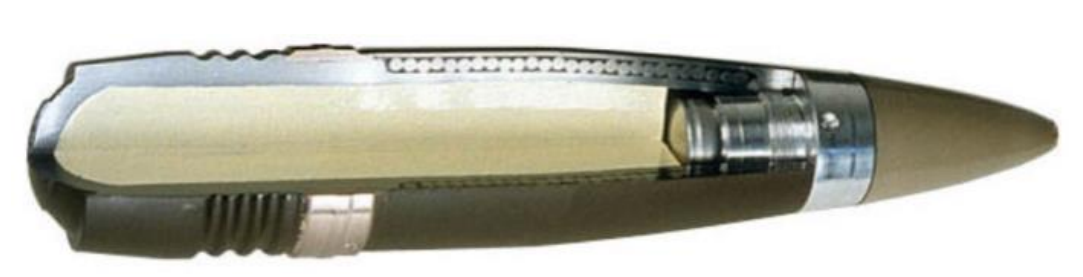

Fig. 8. BOFORS 40/57 mm 3P, Prefragmented Programmable Proximity fuzed projectiles

Ammunition 76mm x 636 for all types (Fig. 9 \& Fig. 10) of OTO Melara Guns $76 \mathrm{~mm} \mathrm{~L} / 62$ which is manufactured by DIEHL Defence has extraordinary solution for HE projectile preformed fragments DM261A2 (HE-PFF) which contains about 2.200 heavy metal balls as preformed fragments diameter of $4 \mathrm{~mm}$.

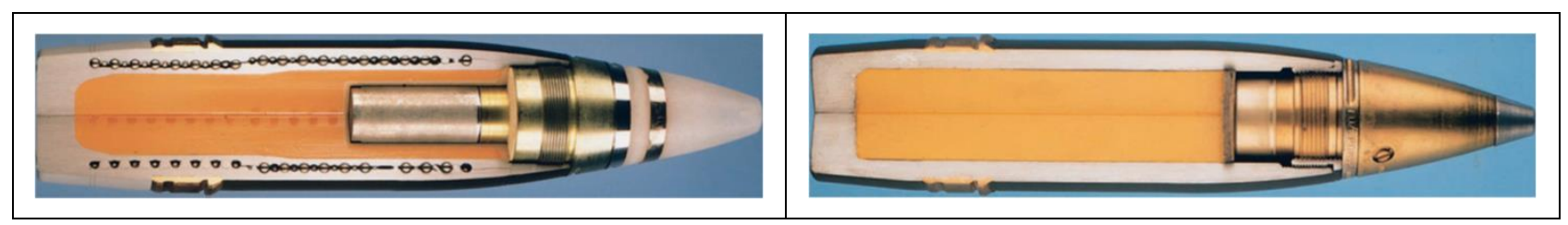

Fig. 9. HE projectile Preformed Fragments Fig. 10. HE Projectile 251 (HE-PD) DM261A2

The first to apply preformed fragments in artillery projectile HE-PFF (High Explosive - Preformed Fragmentation) $105 \mathrm{~mm}$ M1130 with high level of axial acceleration are General Dynamics Ordnance and Tactical Systems (GD-OTS) and Denel Naschem (now Rheinmetall - Denel Munitions teaming arrangement) which was realized within the American concept Advanced Cannon Artillery Ammunition Program (ACA2P) (General Dynamics 2011, Kurzik 2007,). The M1130 HE - PFF has a preformed fragmented (PFF) projectile providing increased lethality compared to current $105 \mathrm{~mm}$ HE projectiles (Fig. 11).

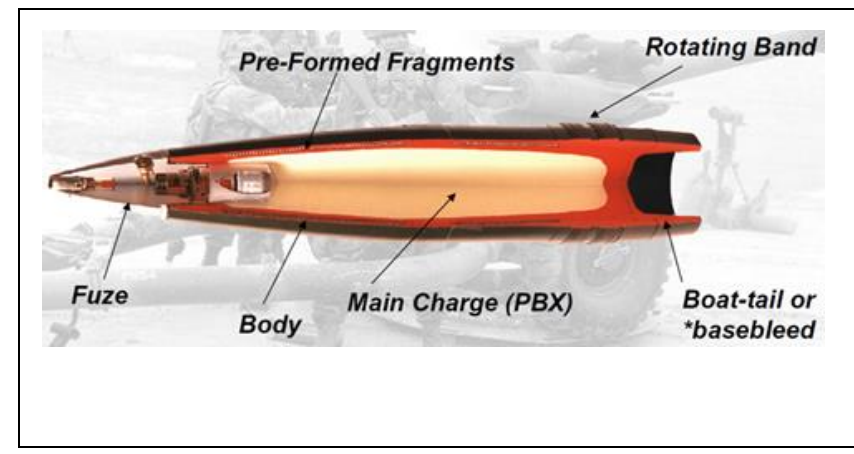

Fig. 11. Projectile HE-PFF (High Explosive - Preformed Fragmentation) $105 \mathrm{~mm}$ M1130

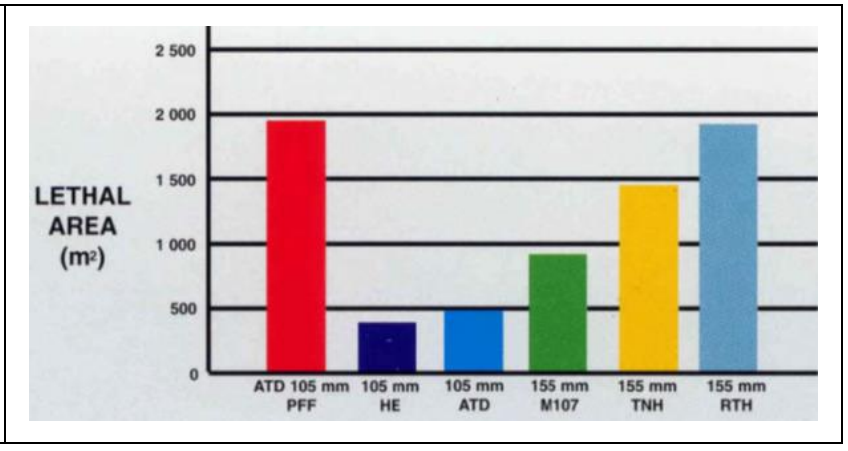

Fig. 12. Lethality area of $105 \mathrm{~mm}$ HEPFF projectile compared to other $105 \& 155 \quad \mathrm{~mm} \quad$ projectiles

[Denel, 2006;GD,2004] 
Zecevic, B.; Terzic, J.; Razic, F. \& Serdarevic-Kadic, S.: Lethal Influence Factors o...

The PFF effect is achieved by the inclusion of tungsten spheres (7.800 tungsten spheres, diameter $3 \mathrm{~mm}$ ) into the matrix in the ogive and cylinder section combined with a natural fragmenting rear body design. Their effectiveness against soft targets exceeds that of a $155 \mathrm{~mm}$ high explosive round. While static lethal area of this projectile is $1900 \mathrm{~m}^{2}$ (Fig. 12), conventional HE artillery projectile $105 \mathrm{~mm} \mathrm{M} 1$ with natural fragmentation lethal area is $500 \mathrm{~m}^{2}$ (Peck, 2006).

Lethality area of $105 \mathrm{~mm} \mathrm{HE}$ - PFF projectile compared to other $105 \mathrm{~mm}$ and $155 \mathrm{~mm}$ projectiles is shown in Figure 13 (Lang, 2013).

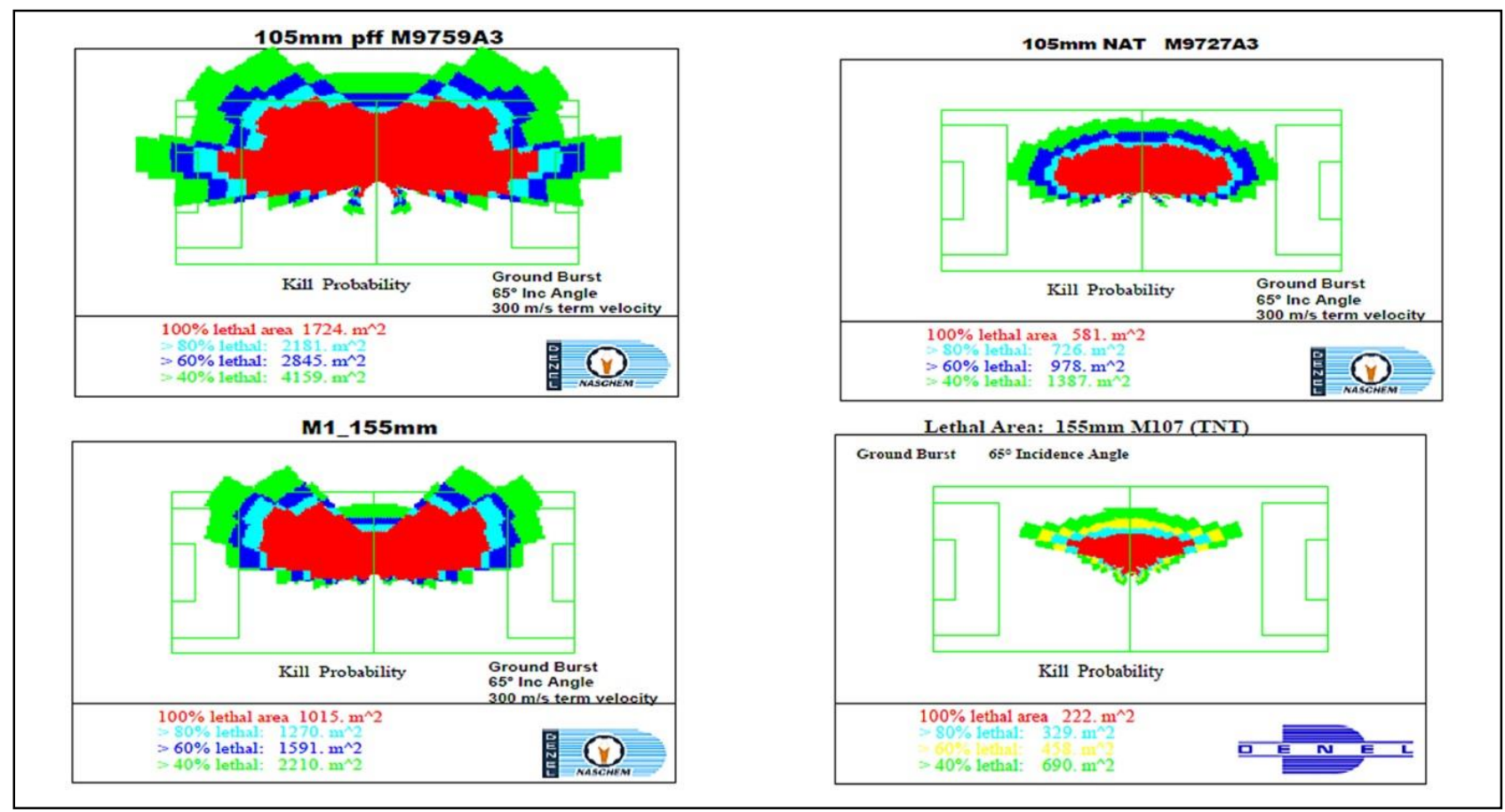

Fig. 13. Lethality area of $105 \mathrm{~mm}$ HE-PFF projectile compared to other $105 \mathrm{~mm}$ and $155 \mathrm{~mm}$ projectiles (Lang, 2013)

Intensive military involvements in urban areas have caused development of projectiles or warheads with Low Collateral Damage (Widener et al., 2012). Technology of preformed fragments is applied in these projectiles, and future research is focused toward varying metal/size and polymer type (Fig. 14).

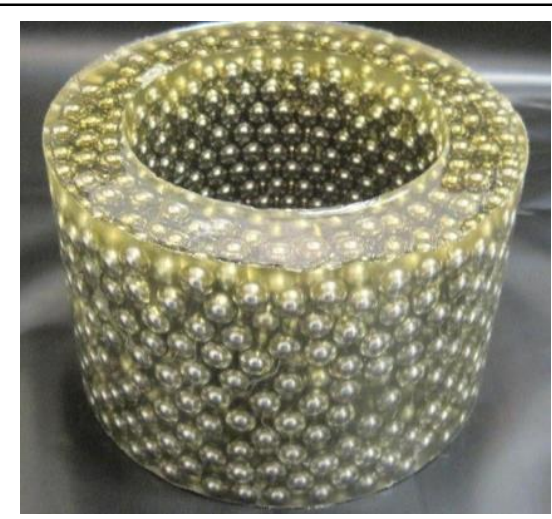

Fig. 14. Preformed fragments (the type of metal) in the matrix cured polymer (Widener et al., 2012) 
Fragments should exhibit several characteristics:

- Good mechanical strength to minimize breakup upon of explosive charge,

- Sufficient density for lethality close in,

- Structure that lends itself to fast oxidation/consumption in air,

- If possible, not require built-inoxidizer, thereby avoiding

- Processing time and cost to manufacture a formulation

- Formulation safety, handling, storage, aging issues.

\section{Embossed fragmentation of projectile}

During the 1970s and 1980s at Naval Air Warfare Center Weapons Division method of controlled fragmentation of warheads called "Pearsons V-notch" was developed (Fig. 15. \& Fig. 16.). It was named after researcher John Pearson. This method is based on the shear-control method for forming fragments of warhead by the detonation products of explosive charge. At the inner side of warhead body notches are formed in a diamond pattern. Depending on the depth, shape (symmetrical or non symmetrical), depth of the notch in relation to the thickness of warhead body, geometrical dimensions, diamond pattern (angles between sides and dimensions of rhombus) efficiency of fragment forming is achieved. At NAWCWD two techniques for notch forming are developed; Pearson notch and the opposed notch techniques (Waggener, 1998; Waggener, 2007).

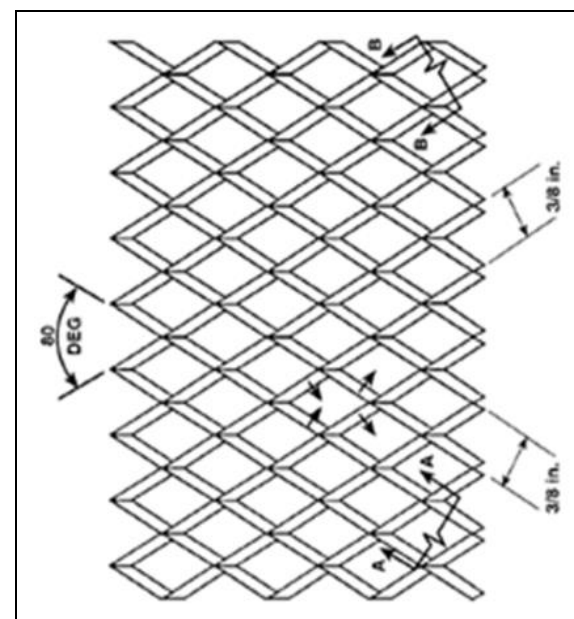

Fig. 15. Diamond Grid Design with Non symmetrical Profiles (Pearson, 1991)

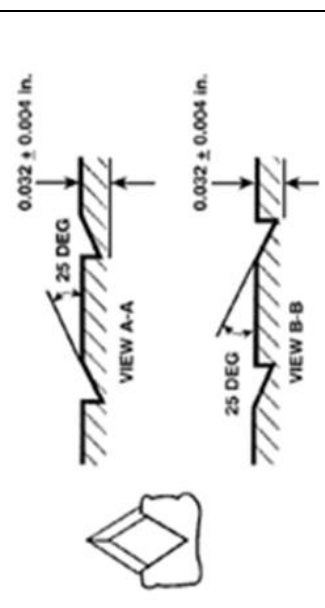

(PearsonV-notch)

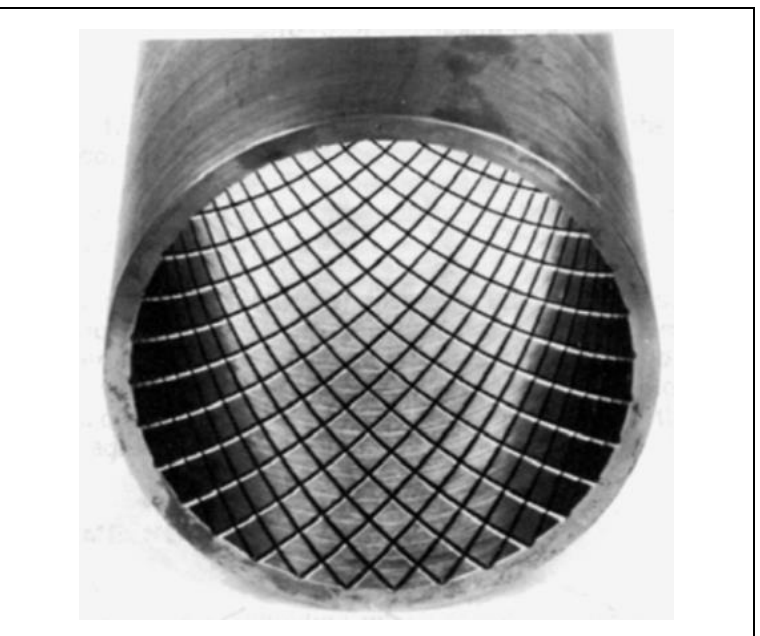

Fig. 16. Steel Cylinder Showing Inner-Surface Diamond-Pattern Grid (Pearson,1991)

The opposed groove method consist of narrow, tapered or straight grooves cut on the inside and outside of the case directly opposite to one another. Both methods allow producing fragments that have desired dimensions with total mass of $80-90 \%$ of warhead body mass. While using these methods it is important to pay attention not to endanger the structural strength of warhead body during launching procedure and contact with the target. Realistically, this method is applicable only for ammunition that is not exposed to high level of axial acceleration at launching phase from weapon. 
Zecevic, B.; Terzic, J.; Razic, F. \& Serdarevic-Kadic, S.: Lethal Influence Factors o...

In the early sixties Russia had started to develop an unguided rocket projectile $122 \mathrm{~mm}$ GRAD with a warhead which used the embossed fragmentation technology. The warhead consisted of the main body and two liners that had „V-notch“" on their outer surfaces (Fig. 17).

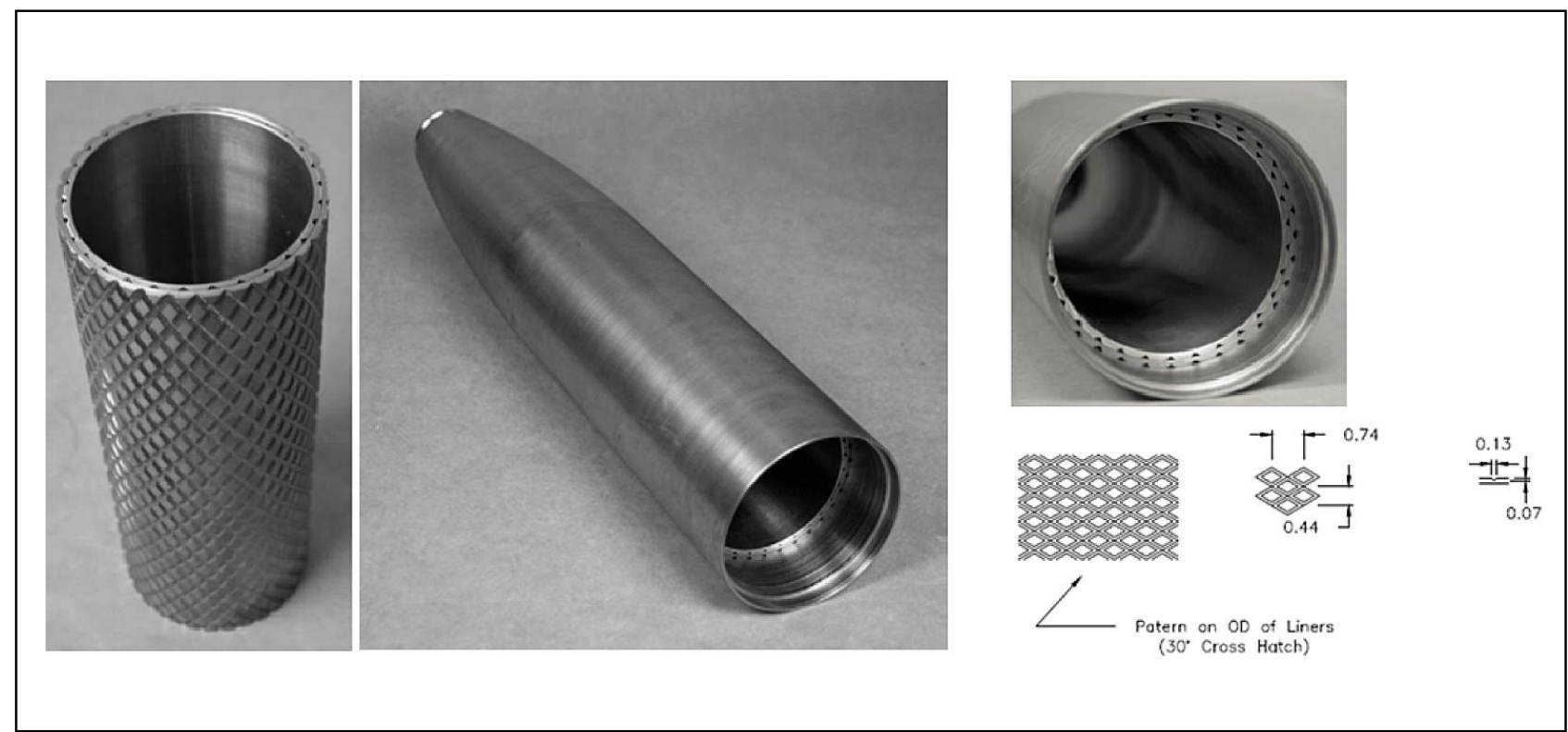

Fig. 17. Characteristics of $122 \mathrm{~mm}$ GRAD 9M22U warhead body (Anon, 2010)

HE rocket 9M22U has $18,4 \mathrm{~kg}$ warhead, which contains $6,4 \mathrm{~kg}$ of explosive AIX-2 (73\% RDX with 23\% Al, flegmatiser with $4 \%$ wax). Inside the warhead's main body are two liners with a total of 1640 diamond shaped fragments that have mass of $2,4 \mathrm{~g}$. the body of warhead consists of 2.280 natural fragments which have a mass of around $2 \mathrm{~g}$. Lethal zone radius of this rocket is a minimum of $25 \mathrm{~m}$ (Fig. 18 \& Fig. 19) from the center of explosion (Fig. 20) (Russian Firearms 2011).

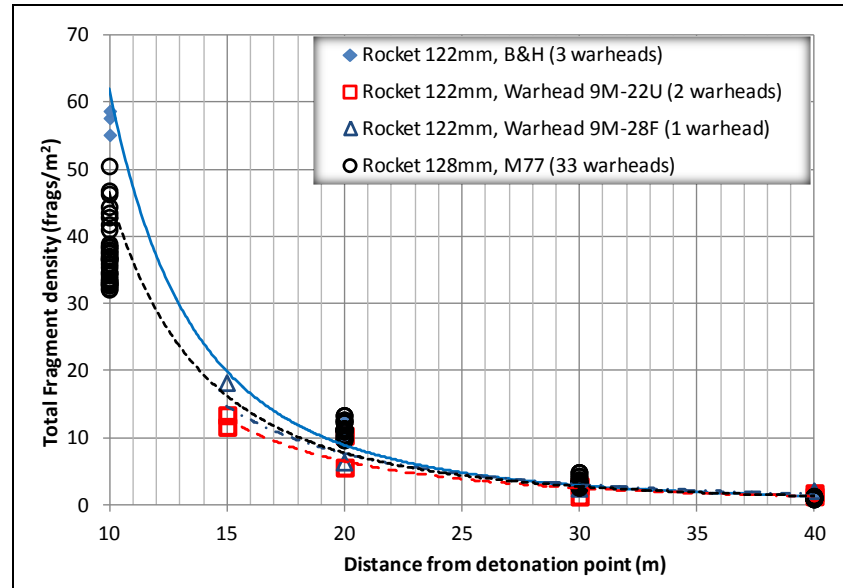

Fig. 18. Change in fragment density as function of distance of centre of explosion

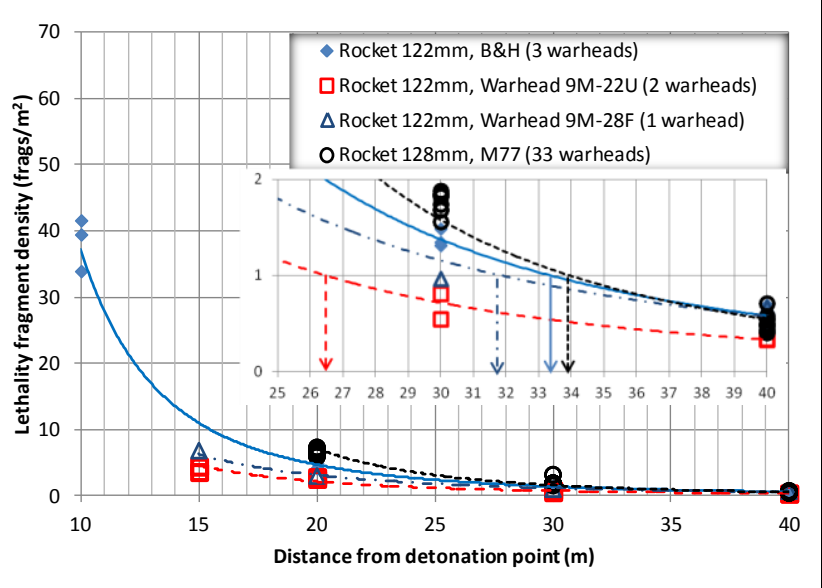

Fig. 19. Change in lethal fragment density as function of distance of centre of explosion 

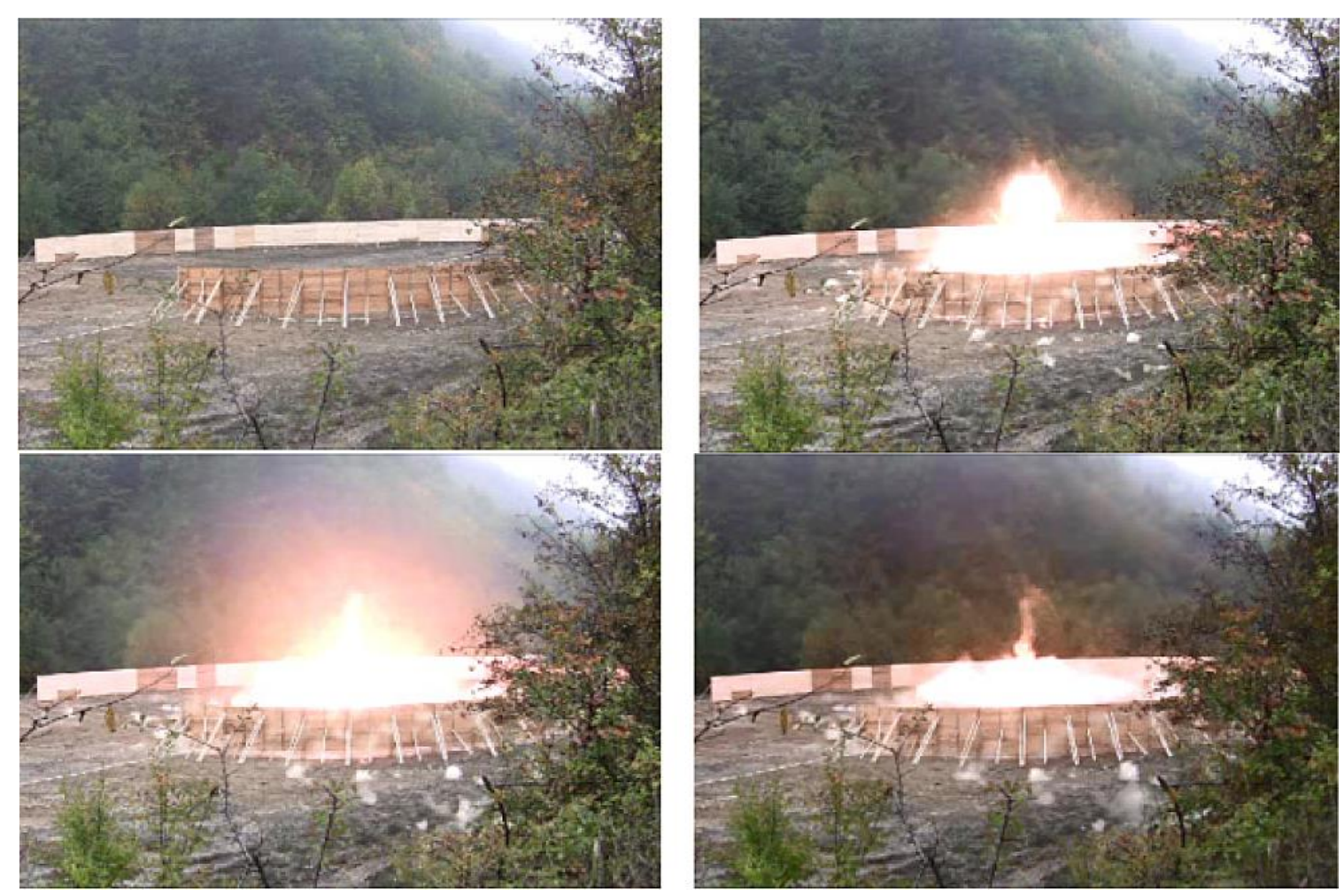

Fig. 20. Fragmentation testing of $\mathrm{HE}$ warhead $122 \mathrm{~mm} 9 \mathrm{M} 22 \mathrm{U}$ in Arena (DTD- database 1994 - 2015)

Test results show different effects of penetration of natural and embossed fragmentation on Celotex panels (Fig. 21) which were placed at 7,6 m distance from centre of explosion.

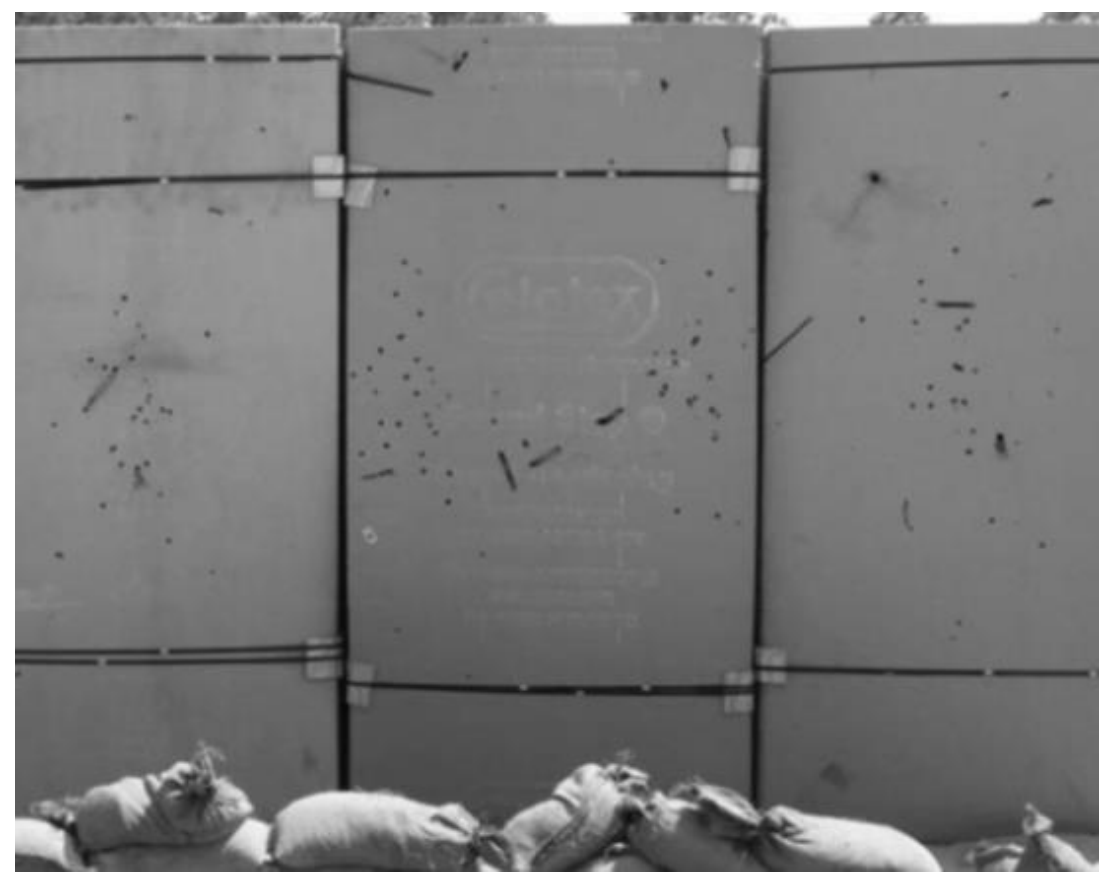

Fig. 21. Effects of natural and embossed fragmentation on Celotex panels after detonation of HE warhead $122 \mathrm{~mm} 9 \mathrm{M} 22 \mathrm{U}$ 
Number of lethal fragments with a minimum energy of $80 \mathrm{~J}$ is from $30 \%$ to $70 \%$ of the total fragment number (Fig. 22), which corresponds to the research done for the $\mathrm{HE}$ artillery projectiles caliber $105 \mathrm{~mm}$ and $155 \mathrm{~mm}$.

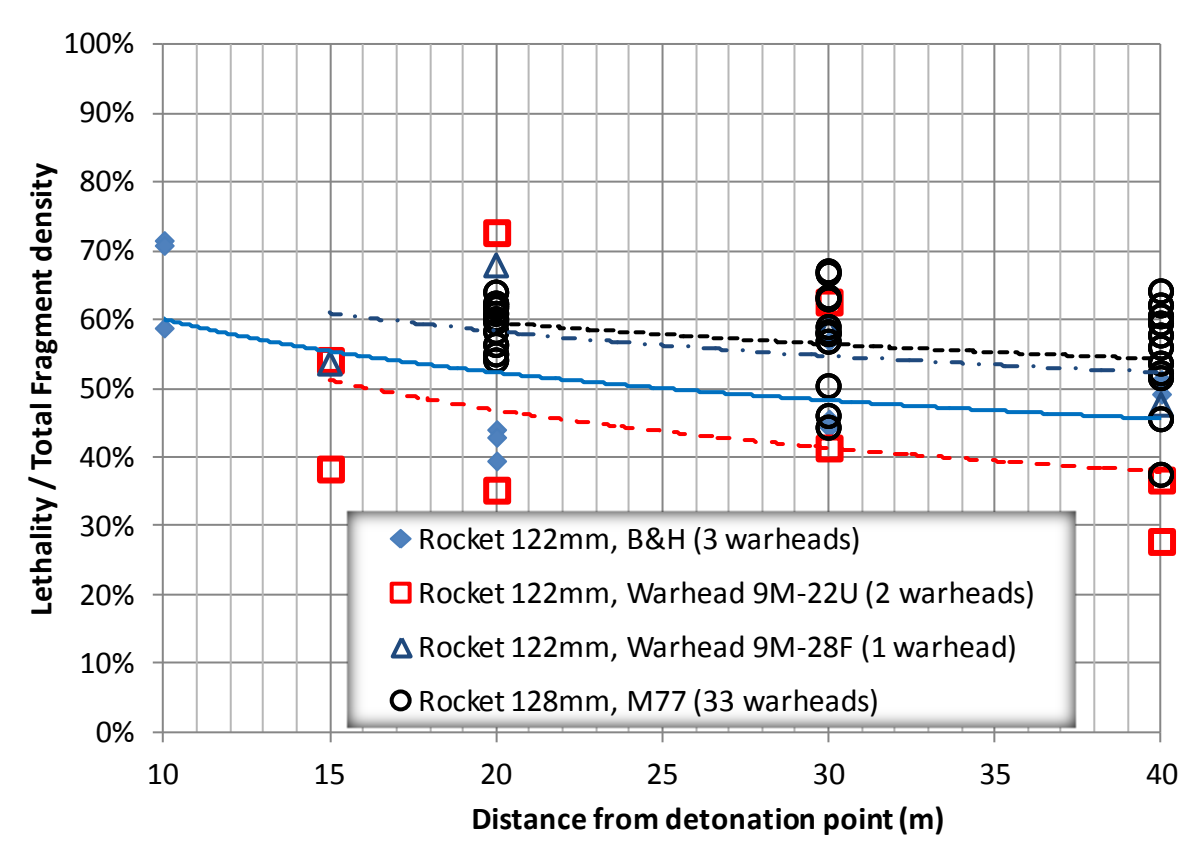

Fig. 22. Contribution of lethal fragments of HE rocket projectile in relation to total number of fragments in the area around explosion, $2 \mathrm{~m}$ height

Instead of embossed technology, HE warhead rocket projectile $128 \mathrm{~mm}$ M77 produced by a company „PRETIS“, Bosnia and Herzegovina, uses preformed fragments. Warhead contains 2.562 pieces of steel spheres with diameter $6,35 \mathrm{~mm}$ and 930 pieces of spheres with diameter of $10,32 \mathrm{~mm}$, which are placed in an epoxy matrix. Explosive charge is mixture of trotyl, hexogen and aluminium and weighs $4,5 \mathrm{~kg}$. Fragments penetrate $8 \mathrm{~mm}$ thick steel armour plates from a 10 meter distance from the centre of explosion, with a penetration density from min. 6 fragments $/ \mathrm{m}^{2}$. Lethality zone is min. $34 \mathrm{~m}$. Company Denel has developed similar HE warhead for rocket 127 $\mathrm{mm}$ for MLRS Valkiri Mk 1.22, which contains 8.500 pieces of steel spheres with a diameter of $6 \mathrm{~mm}$. Lethality area is $1.500 \mathrm{~m}^{2}$.

\section{Conclusion}

Needs for cost reduction of military operations at low intensity battles, which are often taking place in urban areas, have caused development of new types of large caliber projectiles with longer range, more accuracy, preciseness at target and greater lethal efficiency at the target.

Inside the lethal area of natural fragmentation projectile, fragments, all different in shape and mass, are moving mostly at the supersonic velocity. Fragments formed by natural fragmentation process have irregular shape. While flying through the space, multiple shockwaves are formed on their surface which results in sudden drag increase and rapid decrease in its velocity. 
Application of natural fragmentation technologies in modern HE artillery projectiles means possession of high fragmentation steel production technology and thermal procession control of the steel, applying high performance explosives and IM characteristics. Realistically, very few developed countries have this knowledge and technologies.

New trend in application of preformed fragments in modern HE artillery projectiles requires even more specific knowledge and technologies, thereby reducing the number of countries capable of manufacturing modern artillery projectiles with significantly higher lethal efficiency.

Preformed fragment technology in warheads for urban warfare has characteristic of clearly defined lethal zone in order to reduce the collateral damage, especially for the civilians.

For increasing lethal efficiency of warheads for MLRS, all three types of fragmentation are used. Research conducted in Bosnia and Herzegovina show that lethal efficiency of unguided rocket projectiles with preformed fragments has much higher lethal zone than the other two fragmentation technologies, and technologically it is not significantly expensive.

\section{References}

Anon: Development and Fielding of the Excalibur XM982 Warhead, 43rdAnnual Armament Systems: Guns \& Missile Systems Conference \& Exhibition, April 21 -24, 2008, New Orleans, LA

Anon: Engineering Technical Letter (ETL) 10-3: Procedures and Acceptance Criteria for Protective Materials Resistant to $155 \mathrm{~mm}$ and Smaller Fragmenting Munitions, Department Of The Air Force Headquarters Air Force Civil Engineer Support Agency, 2010

Dennis Durkin: Manufacturing Process Development For the OCSW Warhead, Tankautomotive \& Armaments Command,15 August 2001

Dustin Clark, Dedra Moore and Brent Deerman: AMRDEC Lethality Modeling and Simulation Methodologies for Aerial Targets, International Ballistics Symposium, September 2011

Dominick DeMella: Evolution of Artillery for Increased Effectiveness, Armaments Technology Firepower Forum, 2008

Duncan Lang: South Africa-US International Armaments Cooperation (IAC) Framework, 2013

Database of the HE ammunition lethal effects, Defense Technologies Department, Faculty of Mechanical Engineering, University of Sarajevo (1994-2015)

General Dynamics (GD): 105mm LAV III Artillery Weapon System, Light, Lethal, and Deployable! General Dynamics (2004)

Held, Manfred: “Fragmentation Warheads”, book „Tactical Missile Warheads",

Ed. Joseph Carleone, American Institute of Aeronautics and Astronautics, 155 vol. 387-464, 1993.

Jane's Ammunition Handbook 2001-2002, Available from:

http://www.janes.com/extracts/extract/jah/jah_0470.html Accessed: 2015-08-04 
Zecevic, B.; Terzic, J.; Razic, F. \& Serdarevic-Kadic, S.: Lethal Influence Factors o...

Jeffrey F. Widener, Ruslan S. Mudryy, Daniel J. Murphy: Reactive Material Candidates for Low Collateral Damage - Part 1: Arena Testing, 2012 NDIA Insensitive Munitions \& Energetic Materials Technology Symposium, May 14-17, 2012 — Las Vegas, Nevada

Kurzik: XM1131 105mm High Explosive Pre-Formed Fragmentation (PFF) Cartridge, Guns and Missiles Conference, April 23 - 26, 2007

Leo projectile design 105mm, Denel (2006)

Mr Michael Borén: BOFORS 40/57 mm 3P, NDIA, 43. Gun, 2003

Mike Peck, Not Your Father's 105, General Dynamics Land Systems and DENEL, (2006)

Odintsov V., Updating of high explosive projectiles, Bauman Moscow State Technology University, Available from http://milparade.udm.ru/24/contents.htm Accessed: 2010-08-20, (1997)

Odintsov V, Updating of high-explosive projectiles, Military Parade JSC, 6. p. 131, 1997, Available from http://www.milparade.ru/security/24/131.htm Accessed: 201008-20

Pearson, John “A Fragmentation Model Applied to Shear-Control Warheads," Naval Weapons Center, China Lake, NWC TP 7146, May 1991

Richard M. Lloyd, Conventional warhead systems, Physics and engineering design, American Institute of Aeronautics and Astronautics, Vol. 179, 1999.

RUAG Land Systems, Warhead Division: MAPAM ${ }^{\mathrm{TM}}$ - Truly Controlled Fragmentation, 2004

S. S. Waggener: The Evolution of Air Target Warheads, Technology Transition and Dual-Use Technology, Technical Digest, The Naval Surface Warfare Center, Dahlgren Division, , NSWCDD/MP-98/98.

Sam Waggener: THE Evolution Of Air Target Warheads, 23rd International symposium on ballistics Tarragona, SPAIN 16-20 APRIL 2007.

Staffan Harling \& Johan Pelo: "SWERISK - Fast Calculation of Risk in EOD Operations", FOI, Swedish Defence Research Agency, STO-MP-MSG-094, Stockholm, SWEDEN

Zecevic, B; Terzic, J. \& Catovic, A.: Influence of Warhead Design on Natural Fragmentation Performances, Annals of DAAAM for 2004 \& Proceedings of the 15th International DAAAM Symposium, Vienna 2004

Zecevic, B; Terzic, J. \& Catovic, A.: Experimental Research on Influence of Explosive Charge to Natural Fragment Size Distribution, Annals of DAAAM for 2004 \&Proceedings of the 15th International DAAAM Symposium, Vienna 2004

Zecevic, B; Terzic, J. \& Catovic, A.: Influence of Warhead Case Material on Natural Fragmentation Performances, Annals of DAAAM for 2004 \&Proceedings of the 15th International DAAAM Symposium, Vienna 2004

*** Available from http://www.cordin.com/images.html Accessed: 2015-08-18,

105MM M1130 HE-PFF High Explosive - PreFormed Fragmentation, Available from: http://www.gd-ots.com/LCA_105mm_M1130.html Accessed: 2015-08-22 General Dynamics (2011)

*** Http://militaryforces.ru/weapon-3-54-304.html Accessed: 2015.08.05, Multiple Launch Rocket System, Rockets, Russian Firearms 2015 